(c) American Dairy Science Association, 2003.

\title{
Concentration of Polar MFGM Lipids from Buttermilk by Microfiltration and Supercritical Fluid Extraction
}

\author{
J. C. Astaire, ${ }^{\star}$ R. Ward,† J. B. German,† and R. Jiménez-Flores* \\ *Dairy Products Technology Center, Department of Agriculture, California \\ Polytechnic State University, San Luis Obispo, CA 93407 \\ †Department of Food Science, University of California, Davis, Davis, CA 95616
}

\begin{abstract}
Buttermilk contains the milk fat globule membrane (MFGM), a material that possesses many complex lipids that function as nutritionally valuable molecules. Milk-derived sphingolipids and phospholipids affect numerous cell functions, including regulating growth and development, molecular transport systems, stress responses, cross membrane trafficking, and absorption processes. We developed a two-step method to produce buttermilk derivative ingredients containing increased concentrations of the polar MFGM lipids by microfiltration and supercritical fluid extraction (SFE). These processes offer environmentally benign alternatives to conventional lipid fractionation methods that rely on toxic solvents. Firstly, using a ceramic tubular membrane with $0.8-\mu$ pore size, we evaluated the cross flow microfiltration system that maximally concentrated the polar MFGM lipids using a $2^{\mathrm{n}}$ factorial design; the experimental factors were buttermilk source (fresh, or reconstituted from powder) and temperature $\left(50^{\circ} \mathrm{C}\right.$, and $\left.4^{\circ} \mathrm{C}\right)$. Secondly, a SFE process using supercritical carbon dioxide removed exclusively nonpolar lipid material from the microfiltered buttermilk product. Lipid analysis showed that after SFE, the product contained a significantly reduced concentration of nonpolar lipids, and a significantly increased concentration of polar lipids derived from the MFGM. Particle size analysis revealed an impact of SFE on the product structure. The efficiency of the SFE system using the microfiltration-processed powder was compared much more favorably to using buttermilk powder.
\end{abstract}

(Key words: buttermilk, milk fat globule membrane, microfiltration, supercritical fluid extraction)

Abbreviation key: BMP = buttermilk powder, GC = gas chromatography, $\mathbf{M F P}=$ microfiltration fraction

Received December 18, 2002.

Accepted January 23, 2002.

Corresponding author: R. Jiménez-Flores; e-mail: rjimenez@ calpoly.edu. powder, MFGM = milk fat globule membrane, $\mathbf{P C}=$ phosphatidylcholine, PE = phosphatidylethanolamine, $\mathbf{P L}=$ phospholipid, $\mathbf{P S}=$ phosphatidylserine, $\mathbf{S}$ $=$ sphingosine, $\mathbf{S C}-\mathbf{C O}_{\mathbf{2}}=$ supercritical $\mathrm{CO}_{2}, \mathbf{S F E}=$ supercritical fluid extraction, $\mathbf{S L}=$ sphingolipid, $\mathbf{S M}$ $=$ sphingomyelin, $\mathbf{3 X}$ Ret $=$ retentate at $3 \mathrm{X}$ diafiltration factor.

\section{INTRODUCTION}

Complex biological lipids including sphingolipids (SL) and phospholipids (PL) are of interest because they define the structural properties of membranes and lipoproteins, and they also function as intracellular signaling molecules in a variety of biological processes, including regulating cell growth, development, adhesion, and cross membrane trafficking. Complex lipids are also associated with metabolic and age-related diseases, stress responses, and apoptosis (Kim et al., 1991; Hidari et al., 1996; Bajjalieh and Batchelor, 1999; Huwiler et al., 2000; Lightle et al., 2000; Modrak et al., 2002; Okazaki et al., 1989; Sawai and Hannun, 2000). Certain sphingolipids also influence cellular apoptotic pathways and their anti-cancer effects may lead to potential constituents of an anti-cancer regimen, or as health-altering ingredients. These lipids and their roles in apoptotic pathways have been shown to implicate them as beneficial anticancer agents (Dillehay et al., 1994; Parodi, 1997; Nava et al., 2000; Conklin, 2002; Modrak et al., 2002). The SL sphingomyelin (SM), sphingosine (S), sphingosine 1-phosphate, ceramide, and ceramide 1-phosphate, which are metabolites of one another, are of particular interest (Okazaki et al., 1989). Though there is no essential nutritional requirement for SL or PL, research is revealing evidence suggesting a relationship between dietary consumption of these lipids, and enhanced health (Dillehay et al., 1994; Lambertsen and Christiansen, 1997; Kromhout, 2001; Colombo et al., 2002).

SM and other PL of interest are commonly found in the cell membrane, brain and neural tissue, retina, and within some genera of microbes (Batrakov et al., 2000; Huwiler et al., 2000); all are impractical sources 
for lipid isolation. However, buttermilk contains the milk fat globule membrane (MFGM), a material that contains comparatively large amounts of several bioactive SL and PL. The MFGM contains proteins (25 to $60 \%$ ), glycoproteins, carbohydrates, triacylglycerides (TAG), and PL (including SM, phosphatidylcholine (PC), and phosphatidylethanolamine (PE)) (Lambertsen and Christiansen, 1997; Mather, 2000; Walstra et al., 1999; Ye et al., 2002). Buttermilk in particular contains a high percentage of PL compared to regular milk, $0.13 \%$ versus $0.035 \%$ respectively (Walstra et al., 1999). Furthermore, SM represents about one third of its total PL, with PE and PC each contributing roughly a third as well (Parodi, 1997).

Using buttermilk as a source for these lipids is a sound alternative considering its unique properties as a functional ingredient, its low cost, and availability (Walstra et al., 1999). In the U.S., the average monthly production of butter is about 110.2 million pounds; the monthly production of buttermilk is 4.4 to 5.5 million pounds (USDA, 2001). Although there are numerous conventional methods that successfully isolate $\mathrm{PL}$ (Christie, 1982), due to their reliance on solvents that may be toxic to cells in culture, their application would render the products harmful to live cell cultures, unless the solvent is removed completely. The goals of this project were to develop methods for obtaining a product that is nondamaging to organisms and cells. We have found that microfiltration and supercritical fluid extraction (SFE) lead to the selective fractionation of various lipids without the use of conventional toxic solvents.

Traditionally, crossflow microfiltration has been used to concentrate and purify dilute solutions of macromolecules, such as proteins, and lipids. Particularly in the dairy industry, the concentration of lipids, caseins, and whey proteins has responded well to microfiltration systems (Samuelsson, 1997; Cheryan, 1998; Boyd, 1999). Altering the functionality of a product by altering its composition; such as concentrating the microbial loads in fermented products, or minimizing whey proteins in cheese; is a powerful application of microfiltration to the dairy industry, particularly at a time when the nutritional benefits of numerous dairy components make them desirable ingredients (Lambertsen and Christiansen, 1997; Colombo et al., 2002; Conklin, 2002).

$\mathrm{SFE}$ is another method that can selectively fractionate components of a complex mixture. $\mathrm{CO}_{2}$ is a common solvent due primarily to its low critical parameters $\left(31.1^{\circ} \mathrm{C}, 73.8\right.$ bar), low cost, nontoxicity, chemical inertness, and nonflammability (King, 1995; Rozzi and Singh, 2000; Hauthal, 2001). Numerous SFE methods have been developed to extract lipid and lipid soluble materials from complex sources, including (but not limited to) the extraction of lipid-soluble vitamins (A, $\mathrm{D}, \mathrm{E}$, and K), various seed, nut, bean, and wood oils, essential oils, total meat fats, PLs, pesticides, cholesterol, and pharmaceutical components (Hopper and King, 1991; Rónyai et al., 1998; Berg et al., 1997; Montanari et al., 1999; González-Vila et al., 2000; King et al., 2001; Sovová et al., 2001). Often, SFE methods are preferred over conventional methods because the resulting products are free from organic solvent residues, and there is a minimal risk of thermal oxidation. SFE can also offer many of the same benefits derived by other high pressure and carbon dioxide processing practices. Supercritical $\mathrm{CO}_{2}\left(\mathbf{S C}-\mathbf{C O}_{2}\right)$ has been shown to successfully kill a wide range of microbes, vegetative cells, and spores, as well as inactivating deleterious enzymes in certain food products (Enomoto et al., 1997; Stewart et al., 2000; Spilimbergo et al., 2002). $\mathrm{CO}_{2}$ processing is also known to displace oxygen, reduce $\mathrm{pH}$, and penetrate cells rapidly. Furthermore, the process does not cause loss of color, nutrients, or flavor in food (Smelt and Rijke, 1997).

In this paper we present the development of a process to concentrate the polar lipids of the MFGM using microfiltration and SFE.

\section{MATERIALS AND METHODS}

\section{Processing}

Microfiltration and Diafiltration. The microfiltration unit was an in-house manufactured stainless steel shell and tube module containing a GEA Niro brand ceramic membrane (Hudson, WI) with a pore size of $0.8 \mu \mathrm{m}$. The process was driven by a positive displacement pump APV Crepaco Inc. (Lake Mills, WI).

Characterization of buttermilk fractionation using microfiltration focused on a fixed microfiltration membrane pore size $(0.8 \mu \mathrm{m})$, and the two variables to consider were temperature of the process and the source of the buttermilk. A two factorial design $\left(2^{\mathrm{n}}\right)$ was employed for these experiments: temperature conditions of $4^{\circ} \mathrm{C}$ and $50^{\circ} \mathrm{C}$, and origin of the buttermilk as reconstituted from powder, or fresh (churned on site at DPTC pilot plant). These run types are referred to as cold reconstituted, cold fresh, hot reconstituted and hot fresh.

For the reconstituted samples, spray-dried buttermilk powder (product code 26048, Land O'Lakes, Inc., MN) was reconstituted in tap water to give $20 \mathrm{~L}$ of a $10 \%$ total solids solution, and let sit overnight at $4^{\circ} \mathrm{C}$ to fully hydrate. For the fresh samples, fresh cream was obtained from milk of the Cal Poly Dairy, churned on the DPTC pilot plant continuous butter churn (Egli, 
Switzerland), and the buttermilk collected in milk cans and used immediately in the microfiltration system.

The following conditions were employed for all microfiltration processing experiments: each experimental batch represented $20 \mathrm{~L}$ of buttermilk, the total pressure of the system was maintained at approximately $200 \mathrm{psi}$; the inlet was approximately $150 \mathrm{psi}$, and the retentate outlet was approximately $50 \mathrm{psi}$; the transmembrane pressure was maintained at all times at less than 5 psi. The pump was operated at 48 to 54 $\mathrm{Hz}$. The flux rates were recorded for all processes.

The diafiltration process used tap water $(20 \mathrm{~L}$ each addition) to replace the removed permeate volume, beginning when the volume was reduced by $50 \%$ (10 $\mathrm{L}$ ); this was repeated five times. The total water used in the experiment was $100 \mathrm{~L}$ total, in five additions. Throughout the microfiltration and diafiltration process samples were drawn of both the retentate $(\mathbf{R})$ and permeate $(\mathbf{P})$ according to the stage of the diafiltration process, at the point when the batch had the original volume at the retentate tank. Each sample generated samples representing $1,2,3,4$, and 5 volumes of water used for diafiltration. Each set on conditions was repeated three times $(\mathrm{n}=3)$.

Concentration and Spray Drying. The retentate samples were all processed to a $3 \mathrm{X}$ diafiltration factor (R3X) which contained $\sim 3 \%$ TS and then concentrated to total solids of approximately $10 \%$ by ultrafiltration using a 10,000 molecular weight cut off membrane. The same conditions were maintained during ultrafiltration as for the microfiltration processes of each sample. The material was spray dried on a Niro Filterlab Spray Dryer (Hudson, WI) following the manufacturer's instructions. The equipment has a water evaporating capacity of 100 pounds per hour. The spray nozzles had a core of size 16, and the orifice was size 70 ; the pressure was 500 psi. The powdered product was termed MEP.

Supercritical Fluid Extraction. The SFE system and components were acquired from Thar Designs, Inc. (Pittsburgh, PA), including the following: $500 \mathrm{ml}$ vessel, model P-50 high-pressure pump, automated back pressure regulator model BPR-A-200B, and PolyScience brand water bath and pump unit (model 9505). Circulated deionized water at $5^{\circ} \mathrm{C}$ was used for cooling different zones in the SFE apparatus. 50-lb carbon dioxide tanks were filled and inspected by A \& R Welding Supply (San Luis Obispo, CA). The system conditions were controlled manually by Windows 2000-based software (Hewlett-Packard).

Prior to extraction, BMP and MFP were prepared by mixing in a 1:1 ratio with Celite 566 biosilicate (Celite Corporation, Lompoc, CA) to increase extraction efficiency (Berg et al., 1997). It is composed of flux-calcined diatomaceous earth, and is chemically inert and nontoxic. $100 \mathrm{~g}$ of prepared sample was extracted at the following optimal conditions: extraction pressure, 375 bar; extraction temperature, $77^{\circ} \mathrm{C}$; collection temperature, $55^{\circ} \mathrm{C}$; flow rate, $20 \mathrm{~g} / \mathrm{min}$; and extraction time, three cycles of $75 \mathrm{~min}$. The fat extracted was diluted to $10 \mathrm{mg} / \mathrm{ml}$ in chloroform-methanol solution (1:2, v:v). Post extraction the sample name (BMP or MEP) is prefixed with 'defatted'. The BMP extractions were carried out in duplicate, and the MFP extractions in triplicate. The total fat was extracted from the defatted materials in duplicate by Mojonnier Method, and analyzed by TLC following the procedures detailed above. The extraction efficiency was compared between the two systems.

\section{Analysis}

Total Solids and Ash. Total solids were determined using the direct oven drying method for milk using a forced air oven at $100 \pm 1^{\circ} \mathrm{C}$ as described by Marshall (1992). Percent ash was determined by incineration at $550^{\circ} \mathrm{C}$ as described by Marshall (1992).

Protein Determination. Percent protein was determined by testing for total Nitrogen content by the Kjeldahl method (AOAC Official Method 955.04). Samples were heated on a Digestion System 20, model 1015 digester. Samples were distilled with the Kjeldahl System, 1026 Distilling Unit, and FisherTab LCT-40 Kjeldahl Tablets (Fisher Scientific, Tustin, CA) were used as reagent. All samples were analyzed in duplicate. Titrations were done using $0.1 \mathrm{~N} \mathrm{HCl}$, and the percent protein was calculated using the milk protein conversion factor, 6.38. All reagents were of Kjeldahl analysis analytical grade.

Protein Profiling by SDS-PAGE. Samples were diluted in deionized water to yield a protein concentration of $1 \mathrm{mg} / \mathrm{ml}$, and added to reducing-denaturing sample buffer in a 1:1 dilution, vortexed, boiled for 10 minutes, and centrifuged for 2 minutes at $12,000 \times \mathrm{g}$. $10 \mu \mathrm{l}$ was loaded to the gels, and were run at $90 \mathrm{~V}$ through the stacking gel, and $120 \mathrm{~V}$ through the resolving gel. BlueRange Pre-stained Protein Molecular Weight Marker Mix (Pierce, Rockford, IL) was the molecular weight standard. Gels were visualized by staining with Coomassie Brilliant Blue (Sigma Chemical Company, St. Louis, MO). For silver stains, the Silver Stain Plus Kit (Bio-Rad, Hercules, CA) was followed according to manufacturer's protocol. On a particular gel, the intensity of the band indicated the abundance of a particular protein relative to another sample.

Lipid Quantification. The Mojonnier ether extraction method was followed as described by Marshall (1992), for the analysis of buttermilk powder, and but- 
termilk-derived powders. All reagents were of analytical grade, and purchased from Fisher Scientific (Tustin, CA). All samples were extracted in duplicate.

Lipid Profiling by TLC. The following lipid Standards were purchased from Sigma Chemical Co.: SM, PC, PE, phosphatidyl serine (PS), and S. Silica gel glass plates were by Merck (Darmstadt, Germany), and the developing tanks by Kontes Glass Company (New Jersey). All solvents and other reagents were of analytical grade, purchased from Fisher Scientific (Tustin, CA).

Polar lipids were separated using chloroform-methanol-water (65:25:4, v:v); nonpolar lipids were separated using petroleum ether-ethyl ether-acetic acid (85:15:2, v:v). Lipids were prepared in chloroformmethanol $(1: 2, \mathrm{v}: \mathrm{v})$ to $10 \mathrm{mg} / \mathrm{ml}$, and duplicates combined; lipid standards were diluted to $1 \mathrm{mg} / \mathrm{ml} .100 \mu \mathrm{g}$ of sample and $5 \mu \mathrm{g}$ of standard was applied using glass capillaries. Lipids were visualized by exposure to iodine vapor, and then identified by comparison to standards. For a particular plate, the intensity of the spots for a sample indicated the abundance of a particular species relative to another sample (Christie, 1982). The plates were scanned using Vistascan software on a Windows-controlled system (Hewlett-Packard).

Lipid Analysis by GC-MS. The lipids from the powdered samples were extracted in the presence of authentic internal standards by the method of Folch et al. (1957) using chloroform-methanol (2:1, v/v). Preparative TLC, as described previously (Watkins et al., 2001), separated individual lipid classes within each extract. Authentic lipid class standard compounds were spotted on the two outside lanes of the TLC plate to enable localization of the sample lipid classes. Each lipid fraction was scraped from the plate and transesterified in $3 \mathrm{~N}$ methanolic- $\mathrm{HCl}$ in a sealed vial under a nitrogen atmosphere at $100^{\circ} \mathrm{C}$ for $45 \mathrm{~min}$. The resulting fatty acid methyl esters were extracted from the mixture with hexane containing $0.05 \%$ butylated hydroxytoluene and prepared for gas chromatography by sealing the hexane extracts under nitrogen. Fatty acid methyl esters were separated and quantified by capillary gas chromatography using a gas chromatograph (Hewlett-Packard model 6890, Wilmington, DE) equipped with a $30 \mathrm{~m}$ DB-225MS capillary column (J\&W Scientific, Folsom, CA) and a flame-ionization detector as described previously (Watkins et al., 2001).

\section{Particle Size Distribution}

Measurement of particle size distributions. Particle size distributions were determined using a laser diffraction particle size analyzer in the Polarization Intensity Differential Scattering (PIDS) optical mode
(Beckman Coulter, model LS 230, Miami, FL). Diluted powder buttermilk or buttermilk fractions were allowed to re-hydrate for at least $12 \mathrm{~h}$ at $10 \% \mathrm{TS}$ solutions. Then each sample was added into the analysis chamber containing $1 \mathrm{~L} \mathrm{PBS}$, until the required obscuration (about 50\%) was achieved, pump speed, 10\%; laser power, $84 \%, 57.8 \mathrm{~mA}$; run length, $61 \mathrm{~s}$; temperature, 23 to $25^{\circ} \mathrm{C}$. The PIDS system uses three wavelengths of light ( $450 \mathrm{~nm}, 600 \mathrm{~nm}$, and $900 \mathrm{~nm}$ ) at two polarizations. Measurements are made at several scattering angles of the light polarized vertical to the scattering plane and the light polarized horizontal to the scattering plane. The difference in scattered intensity between the two polarizations is highly sensitive to particle size, wavelength and angle of measurement. PIDS system has the highest resolution when the particle size is smaller than the wavelength, i.e., in the 100 - to $400-\mathrm{nm}$ range.

\section{Statistical Analysis}

All comparisons were done by Analysis of Variance with Tukey's pairwise comparisons using Minitab software 13.0. Values of $P=0.05$ were considered statistically significant.

\section{RESULTS}

\section{Microfiltration}

No significant difference $(P<0.05)$ was found in the processing parameters or the composition of collected permeates and retentates samples between each of the three repetition trials for each set of variables. These results allowed us to pool the samples for each particular set of conditions for further analysis.

The data demonstrated that for concentration of phospholipids from buttermilk the optimal diafiltration was achieved at $3 \mathrm{X}$ the original volume using a microfiltration membrane (with pores of $0.8 \mu \mathrm{m}$; Vyas et al., 2002, results therein not shown). Therefore all our results are presented here for the $3 \mathrm{X}$ diafiltration set of samples. For the remainder of the paper, permeate and retentate samples at this point are called P3X and R3X respectively.

Table 1 presents the result of the composition analysis in dry matter basis for each of the starting buttermilk sources and the resulting R3X and P3X for each temperature considered in the process.

Table 2 summarizes the composition comparison between the initial buttermilk composition and the resulting R3X for each of the four processes considered. In addition to the data from Table 1, we also present data for casein, whey, MFGM proteins, MFGM lipids and nonpolar lipids. For each comparison presented 
Table 1. Compositional data on a dry matter basis for reconstituted and fresh buttermilk, and the $3 \mathrm{X}$ Retentates processed by microfiltration with experimental factors of temperature $\left(4^{\circ} \mathrm{C}\right.$ or $\left.50^{\circ} \mathrm{C}\right)$, and buttermilk source (reconstituted or fresh).

\begin{tabular}{lrlrr}
\hline Sample & \multicolumn{1}{c}{$\%$ Fat } & \% Protein & \% Ash & \% Lactose $^{\mathrm{a}}$ \\
\hline Recon. ${ }^{1}$ Buttermilk & $4.56 \pm 0.45$ & $35.46 \pm 1.49$ & $7.49 \pm 0.52$ & 52.49 \\
R3X ${ }^{\circ} 4^{\circ} \mathrm{C}$, Recon. & $8.46 \pm 1.80$ & $83.02 \pm 7.63$ & $7.97 \pm 0.43$ & 0.55 \\
R3X: $50^{\circ} \mathrm{C}$, Recon. & $9.00 \pm 1.07$ & $57.98 \pm 1.55$ & $16.05 \pm 1.97$ & 16.97 \\
Fresh Buttermilk & $10.15 \pm 0.95$ & $31.60 \pm 3.33$ & $6.52 \pm 0.47$ & 51.73 \\
R3X: $4^{\circ} \mathrm{C}$, Fresh & $37.12 \pm 3.14$ & $42.84 \pm 4.61$ & $6.02 \pm 1.53$ & 14.02 \\
R3X: $50^{\circ} \mathrm{C}$, Fresh & $3.24 \pm 1.71$ & $55.20 \pm 2.65$ & $8.73 \pm 2.10$ & 32.83 \\
\hline
\end{tabular}

${ }^{1}$ Recon. $=$ Reconstituted (from powder).

${ }^{2} \mathrm{R} 3 \mathrm{X}=$ Retentate diafiltered to a $3 \mathrm{X}$ concentration factor.

a\% Lactose was calculated by difference.

in Table 2, only three options are presented increase in concentration, decrease in concentration or no change. Each of these options is considered only when the difference between the sample and the original buttermilk is significantly different after statistical analysis $(P<0.05)$.

It is interesting to note that each process yielded a different specificity for the concentration or dilution of the different components in the retentate. Total fat as percent of the solids retained increased in all the treatments except in hot fresh, but the MFGM lipids increased only in the cold reconstituted process. At the same time, the nonpolar lipids did hot changed in hot fresh or cold reconstituted, while increased significantly in cold fresh and hot reconstituted processes. In relation to the protein content of the different retentates obtained, it was clear that the whey protein content did not vary in any of the processes, while casein decreased significantly in all except hot reconstituted. Also the results indicate that independently of the

Table 2. The effect of microfiltration to a $3 \mathrm{X}$ diafiltration factor in the retentate on the relative concentrations of various components from the starting buttermilk material in the four experimental systems.

\begin{tabular}{|c|c|c|c|c|}
\hline Component & $\begin{array}{l}\text { Cold } \\
\text { reconstituted }\end{array}$ & $\begin{array}{l}\text { Hot } \\
\text { reconstituted }\end{array}$ & $\begin{array}{l}\text { Cold } \\
\text { fresh }\end{array}$ & $\begin{array}{l}\text { Hot } \\
\text { fresh }\end{array}$ \\
\hline Total fat & $t^{\mathrm{a}}$ & + & + & $-^{\mathrm{a}}$ \\
\hline MFGM lipids ${ }^{1}$ & + & - & - & - \\
\hline Nonpolar lipids ${ }^{1}$ & $\mathrm{nc}^{\mathrm{a}}$ & + & + & nc \\
\hline Total protein & + & + & + & + \\
\hline MFGM proteins ${ }^{1}$ & + & $\mathrm{nc}$ & + & $\mathrm{nc}$ \\
\hline Caseins $^{1}$ & - & $\mathrm{nc}$ & - & - \\
\hline Whey proteins ${ }^{1}$ & nc & nc & nc & nc \\
\hline Ash & $\mathrm{nc}$ & + & nc & + \\
\hline Lactose & - & - & - & - \\
\hline
\end{tabular}

${ }^{a}$ Compared to the starting buttermilk material, ' + ' indicates a significant increase in concentration, "-" indicates a significant decrease in concentration, and "nc" indicates no significant change in concentration. Samples with $P<0.05$ were judged significant.

${ }^{1}$ These components were judged additionally by visual comparison with the starting buttermilk material analyzed on the same plate/ gel with equal concentrations analyzed. source of buttermilk, there is a tendency to retain the MFGM proteins in the cold treatments, while the hot treatments did not change significant the content of these proteins.

Surprisingly, there was no correlation between the retention of MFGM proteins and lipids in these trials. Also with high temperature there was a concomitant retention of minerals. Lactose was significantly reduced in all the samples.

\section{Supercritical Fluid Extraction and Lipid Profiles by TLC}

Triplicate runs of SFE demonstrated that total fat was consistently reduced from approximately 9 to $3.5 \%$ (a reduction of 38\%) in the retentate fractions, while the same process only reduced the buttermilk powders from 5 to $1.5 \%$ (reduction of $30 \%$ ). These changes were statistically significant $(P<0.05)$. Analysis of the lipids by TLC demonstrates that the lipids present in the retentates after SFE were in its majority polar lipids while the removed fraction were composed exclusively of non-polar lipids. Figures 1 and 2 illustrate these results for all the trials of SFE extractions. Figure 1 is a picture of the TLC analysis of the polar lipids from either the original buttermilk or the microfiltration fraction, and the results of the three repetitions of the SFE process, showing the extracted lipids and those left in the sample. Although the same amount of lipids was loaded in each spot, a higher concentration of all the polar lipids is noticeable in the lipids remaining in the sample as can be seen in lanes 3,5 , and 7 . It is clear that SFE extracted only nonpolar lipids from either BMP or MFP. Figure 2, a TLC for separation of nonpolar lipids, clearly demonstrates that the lipids carried from the samples by SFE had no residual polar lipids, as can be seen at the origins of application in lanes 5, 7, and 9 . 


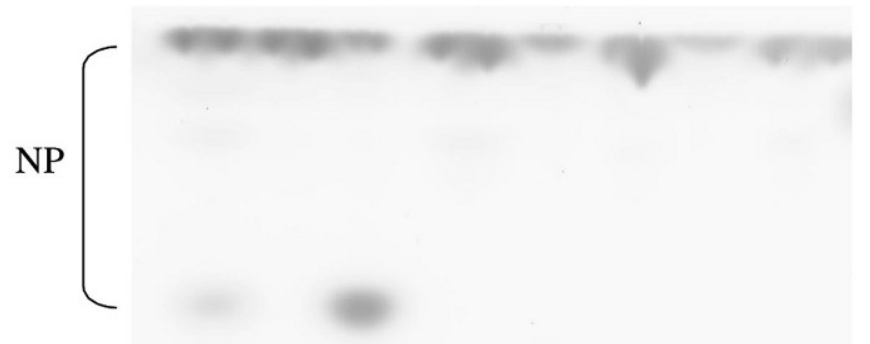

PE

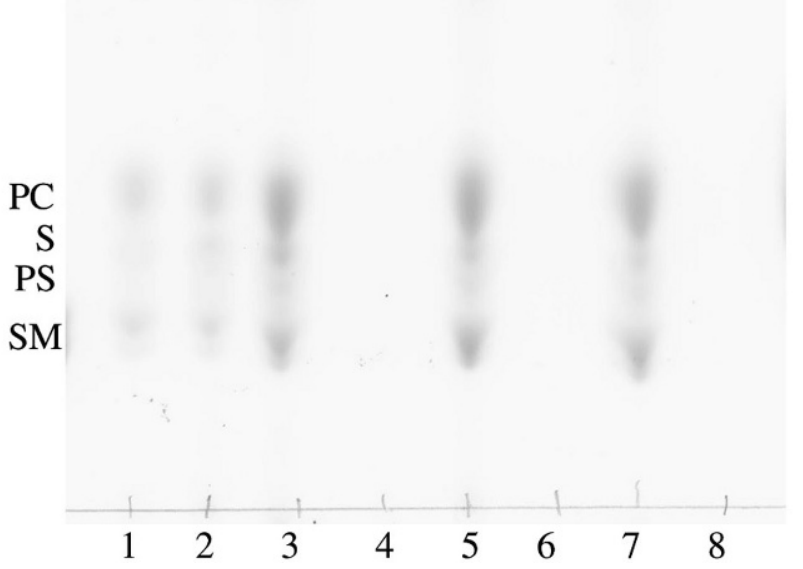

Figure 1. Thin layer chromatograph showing polar lipid profiles from three SFE trials (A, B, and C) with microfiltration-enriched powder using the chloroform-methanol-water $(65: 25: 4, \mathrm{v}: \mathrm{v})$ solvent system. Sample order is as follows: lane 1, buttermilk; 2, microfiltration-enriched powder; 3 , trial A microfiltration-enriched powder after $\mathrm{SFE} ; 4$, trial A removed fat; 5 , trial B microfiltration-enriched powder after SFE; 6 , trial $\mathrm{B}$ removed fat; 7 , trial $\mathrm{C}$ microfiltration-enriched powder after SFE; 8 , trial C removed fat. Abbreviations are as follows in order from bottom to top: $\mathrm{SM}$ = sphingomyelin, $\mathrm{PS}$ = phosphatidyl serine, $\mathrm{S}=$ sphingosine, $\mathrm{PC}=$ phosphatidylcholine, $\mathrm{PE}=$ phosphatidylethanolamine, $\mathrm{NP}=$ nonpolar.

\section{Lipid Composition Changes Due to SFE by GC}

Lipid analysis by capillary GC of the triplicate SFE runs using MFP gave specific concentrations of total TAG, polar lipids, and fatty acids; this data is given in Table 3. In agreement with the lipid profiles by TLC, after SFE the MFP showed a significant decrease in TAG concentration and a significant increase in PL concentration. Most significant, the change in MFP polar lipid content goes from 9.5 to 19.7 , while at the same time the triglycerides are reduced from 21.3 to
Chol

Esters

TAGs

FFAs

Chol

DAGs [

MAGs

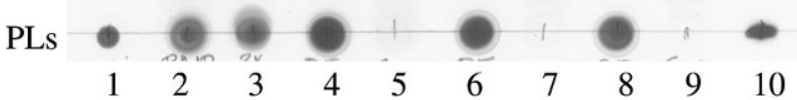

Figure 2. Thin layer chromatograph showing nonpolar lipid profiles from three SFE trials (A, B, and C) with microfiltration-enriched powder using the petroleum ether-ethyl ether-acetic acid (85:15:2, v:v) solvent system. Sample order is as follows: lane 1, phosphatidylethanolamine; 2 , buttermilk; 3 , microfiltration-enriched powder; 4 , trial A microfiltration-enriched powder after SFE; 5, trial A removed fat; 6 , trial B microfiltration-enriched powder after SFE; 7, trial B removed fat; 8 , trial $C$ enrichment powder after SFE; 9 , trial $\mathrm{C}$ removed fat; 10, sphingomyelin. Abbreviations are as follows in order from bottom to top: PLs = phospholipids, MAGs = monoacylglycerides, DAGs $=$ diacylglycerides, $\mathrm{Chol}=$ Cholesterol, FFAs $=$ free fatty acids, TAGs $=$ triacylglycerides, Chol Esters $=$ cholesterol esters.

approximately 4 . This indicates an enrichment of polar lipids in the defatted MFP of five fold over the triglycerides.

Total fatty acid analysis of the lipid fractions showed that lipids containing fatty acids of short and medium length (less than and equal to C18:1) decreased in concentration after SFE, while lipids that contained fatty acids of long chain length (in the range from C18:2 to C24) increased in concentration. It must be noted that the SFE extraction was performed on the $\mathrm{BM}$ and MFP, while FA analysis was performed on the lipids extracted by the Mojonnier method. 
Table 3. Lipid and fatty acid concentrations of the MFP and Defatted MFP as determined by capillary GC analysis.

\begin{tabular}{lcc}
\hline Lipid component & $\begin{array}{l}\text { MFP } \\
(\mathrm{mg} \text { lipid/g dry powder })\end{array}$ & $\begin{array}{c}\text { Defatted MFP } \\
(\mathrm{mg} \text { lipid/g dry powder) }\end{array}$ \\
\hline Triacylglycerides & $21.33 \pm 2.55$ & $3.98 \pm 1.87$ \\
Total Polar Lipids & $9.59 \pm 0.28$ & $19.74 \pm 1.55$ \\
PC $^{3}$ & $6.24 \pm 0.27$ & $12.12 \pm 0.46$ \\
$\begin{array}{l}\text { Total short and medium } \\
\text { chain fatty acids }=\text { C18: }\end{array}$ & $36.68 \pm 0.73$ & $19.56 \pm 1.87$ \\
$\begin{array}{l}\text { Total long chain fatty } \\
\text { acids C18n2 to C24: }\end{array}$ & $3.25 \pm 0.18$ & $4.75 \pm 0.35$ \\
\hline
\end{tabular}

\footnotetext{
${ }^{1} \mathrm{MFP}=$ microfiltration-fraction powder.

${ }^{2}$ 'Defatted' refers to the MFP after supercritical fluid extraction.

${ }^{3} \mathrm{PC}=$ Phosphatidylcholine.
}

\section{Particle Size Distribution}

BMP and MFP before and after SFE treatment were reconstituted and analyzed under exactly the same conditions for determining their particle distribution profile. The samples considered showed great reproducibility. The particle size profile of the buttermilk clearly shows peaks that could correspond to the different kind of particles expected; casein micelles and micelle aggregates between 0.04 and $0.2 \mu \mathrm{m}$, skim residual MFGM particles and aggregates between 0.3 and $4 \mu \mathrm{m}$. However these structures are clearly affected by the changes induced by SFE. The prolonged heat $\left(70^{\circ} \mathrm{C}\right)$ for the three extractions, and the change in lipid composition, yielded very different curves for these powders after extraction (Figure 3). Buttermilk particles present in the reconstituted and extracted sam- ples were much larger than those from the retentates. It is clear, however, that the effect of SFE was much larger on the structure of BMP than on MFP.

\section{DISCUSSION}

The objective of the microfiltration process was to maximally concentrate the polar lipids of the MFGM, namely SM, PS, PC, and PE, on a pilot plant scale (20 L) using a membrane with a pore size of $0.8 \mu \mathrm{m}$. The first phase of this process was based on microfiltration fractionation of buttermilk. In previous experiments using this system we determined that the major efficiency for phospholipids enrichment of buttermilk fractions are $3 \mathrm{X}$ diafiltration. Less than $3 \mathrm{X}$ the protein to phospholipids ratio changed little with respect to buttermilk, and more than $3 \mathrm{X}$ the actual increase in

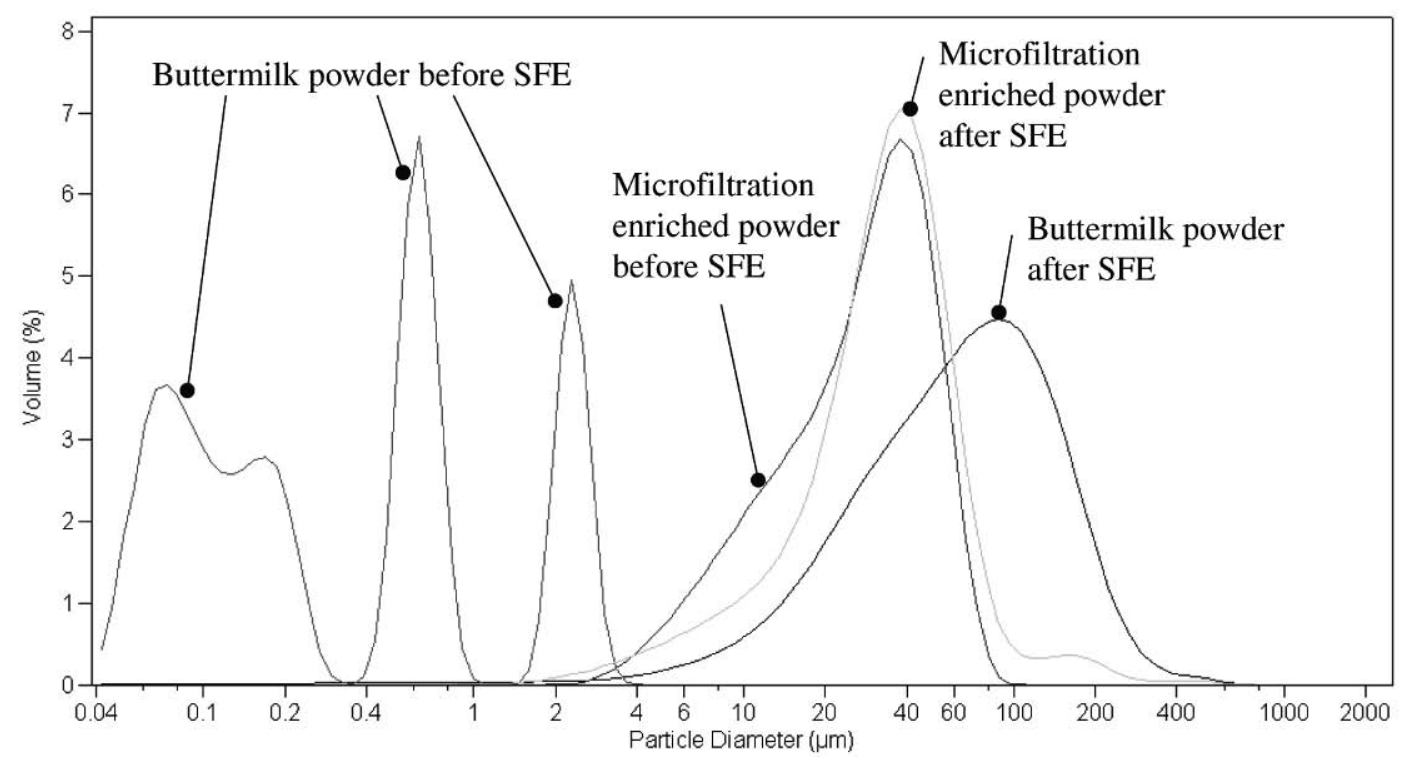

Figure 3. Particle size distributions given in volume percent of buttermilk powder and the microfiltration-enriched powder before, and after SFE are shown. 
protein to phospholipids ratio is not very large and very costly in processing terms. Thus, in this paper the extent of diafiltration is fixed to 3X (total use of $60 \mathrm{~L}$ of water for $20 \mathrm{~L}$ of buttermilk).

The analysis of the microfiltration fractions for this work focused on two aspects related to the process: the changes in the composition of the total protein, fat, and ash; and the specific compositional profiles of the proteins and lipids in the fractions (Tables 1 and 2).

Changes in composition were sensitive to both variables considered. The effect of temperature was most significant in changes on the fat as percent of total solids. While the fat close to doubled in the reconstituted buttermilk whether at cold or hot conditions, fresh buttermilk was most sensitive to this change. Under cold conditions the fat content increases to almost four fold, while hot there is a three-fold decrease in total fat. This part can be partially explained by the fact that the average fat content of fresh buttermilk was much higher than that of the reconstituted BM, and most of that fat was in the form of triglycerides.

Protein retention was mostly sensitive to the source of the buttermilk. Either hot or cold, protein content was higher on the reconstituted buttermilk, with the highest retention shown at cold temperature. Fresh buttermilk protein retention was almost insensitive to the process temperature. A possible explanation to the above-mentioned differences may reside in the actual physical state of the components of buttermilk once they are made into powder, and then reconstituted for our experiments. The heat treatment and spray drying process used in buttermilk powder manufacture could increase the retention of the polar MFGM lipids, particularly if the structure of the MFGM complex was affected. The formation of high molecular weight complexes through crosslinking of proteins or other components with the MFGM (Kim and JiménezFlores, 1995; Lefèvre and Subirade, 2000) would increase the size, thereby increasing its retention in the filtration process. This is actually confirmed by our particle size analysis discussed below.

Another way to analyze the changes occurred is by considering the temperature of processing. In normal industrial operations, milk and milk products are handled either at a cold temperature of $4^{\circ} \mathrm{C}$, or at a processing temperature of $50^{\circ} \mathrm{C}$. When cold temperatures are used, the aim is conservation, while high temperatures have the objective of lower viscosity and increase efficiency. Because it is generally recognized that lipids become more fluid under warm conditions, we hypothesized that using cold conditions would retain the lipid materials more effectively. Though the processing time with cold conditions is much longer than with hot conditions (approximately $24 \mathrm{~h}$ versus $8 \mathrm{~h}$ ), the lipid profiles indicated that the cold conditions using reconstituted buttermilk retained the polar lipids of the MFGM more efficiently as can be seen in Table 2. While total fat, MFGM lipids and nonpolar lipids all increased in their proportions in the cold reconstituted process, they all decreased for the hot fresh process. Furthermore, in the hot reconstituted system, lipid profiles indicated that the nonpolar lipids, particularly cholesterol, and the mono- and diglycerides, were retained preferentially.

These differences in composition in relation to temperature can also be explained in part by the properties of the lipids. The hot conditions could be increasing the permeability of the MFGM and any of its complexes through the pores of the microfiltration membrane. The structure in BM containing the PL of the MFGM, like other biological membrane systems, is naturally less rigid in structure than other lipids, such as cholesterol and saturated triglycerides (micrographs of BM present fragmented membranes). Perhaps the increased temperature was such that more rigid lipids were retained due to their stable structures, and lipids with lower melting points and/or more compact structures, such as those found in the MFGM and other unsaturated fats, permeated through the microfiltration membrane easier at the higher temperature than when the process was kept cold. Only cold fresh MFGM lipids show a decrease compared to their original BM, however this is due to the very high content of triglycerides in the starting material, and some retention of large fat globules would override the retention effect that the membrane process could have.

Focusing on the protein content of the samples, as could be expected, there was a marked difference between the partition of caseins and whey proteins. In the cold reconstituted system it was clear that with increased diafiltration, the amounts of caseins decreased; this phenomenon was observed in the fresh samples as well. Specifically, $\beta$-casein and $\kappa$-casein contents were markedly different between the hot and cold runs (SDS-PAGE results not shown). This is in agreement with the documented solubilization behavior of $\beta$-casein at a low temperature, and casein micelle disruption at a low temperature in microfiltration systems (Walstra, 1999). The proteins of the MFGM were more concentrated in the retentate samples than in the permeate samples, indicating the presence of the MFGM. The hot conditions showed decreased retentions of the MFGM proteins in both the reconstituted and fresh buttermilks, and the cold fresh system did not show a marked change in the concentration of the MFGM proteins from the starting buttermilk. However, the proportion of whey proteins did not change, while lactose was reduced significantly in all cases. 
This demonstrates that whey proteins are crosslinked or somehow attached to the components of MFGM.

The microfiltration system using cold conditions and reconstituted buttermilk diafiltered to a $3 \mathrm{X}$ factor concentrated the polar lipids of the MFGM most efficiently; however, approximately half of the remaining lipid was nonpolar in nature. These nonpolar lipids; composed primarily of triacylglycerides, cholesterol, and free fatty acids; were not necessarily desirable constituents of the final product. Diets high in these types of fats are associated with increased health risks (Kromhout, 2001; Conklin, 2002). An additional processing step using SFE with $\mathrm{SC}-\mathrm{CO}_{2}$ to remove the nonpolar lipids would leave the remaining fraction with lipids composed of the polar MFGM lipids; it would also be safe for consumption, or cell culturebased research. Furthermore, this processing would likely deactivate microbes and endospores (Enomoto et al., 1997; Stewart et al., 2000; Spilimbergo et al., 2002).

SFE successfully increased the concentration of the polar MFGM lipids (namely SM, PC, and PE) in BMP, and the MFP by removing exclusively nonpolar lipid material. Because the total fat therein is composed of various polar and nonpolar species, removing exclusively nonpolar lipids from the powder left the remaining fraction consisting primarily of polar MFGM lipids. Quantitative TLC lipid profiles showed that after SFE, the MFP contained a higher concentration and increased purity of the MFGM lipids. Capillary GC further corroborated these findings by revealing a significant decrease in TAG concentration, and a significant increase in total PL concentration in the MEP. The extraction also showed a higher efficiency in the MFP than in the BMP, removing a greater portion of the nonpolar lipids.

Though the BMP retained approximately one third of its original content of fat after SFE, the total fat was significantly reduced from $5 \%$ to $1.7 \%$. Most significantly Table 3 demonstrates the dramatic enrichment of polar lipids (PE, PC, SM), which represented five fold the amount of triglycerides present in the fraction. However, in BMP there was not a clear increase in concentration of the MFGM lipids just by SFE treatment. The SFE process was not as efficient with the BMP as with the MEP; all MFP trials showed a dramatic reduction in nonpolar lipids, evident in the profiles given in Figure 2. It has been previously demonstrated that the presence of lactose could interfere with the SFE process (Turner and Mathiasson, 2000). Since our microfiltration system was such that the MFP contained less than 1\% lactose, the lower extraction efficiency seen in the BMP could be explained by the presence of lactose in the latter. Alternatively, the microfiltration process also reduced some of the small components such as casein micelles that may influence the manner in which SFE carries the lipids away from the powders. These results demonstrate the value of our approach on combining MF and SFE to produce these MFGM ingredients.

Although SFE removed the majority of the nonpolar lipid material in the MEP, some of these lipids remained in the powder. In our results we analyzed only 3 cycles of extraction; a fourth extraction cycle removed slightly more lipid, but it was not significant enough to warrant the increased processing time. The fact that some non-polar lipids remained in the SFE treated samples suggests that the nonpolar lipids in the powder have different solubility in $\mathrm{SC}-\mathrm{CO}_{2}$. It is generally recognized that $\mathrm{MW}$ of the lipids also play a role in their affinity to $\mathrm{SC}-\mathrm{CO}_{2}$. It has been demonstrated (Markom et al., 2001) that triglycerides rich in saturated fatty acids with lower molecular weights (C12:0, C14:0, and C16:0) were more soluble in SC$\mathrm{CO}_{2}$ than were triglycerides rich in unsaturated fats with higher molecular weights (C18:1, C18:3, C20:0). This is consistent with the observation that lipids containing fatty acids of short and medium chain length $=\mathrm{C} 18: 1$ showed a greater solubility in $\mathrm{SC}-\mathrm{CO}_{2}$ than did lipids containing fatty acids in the long chain range of $\mathrm{C} 18$ to $\mathrm{C} 24$; the former showed a decrease in concentration while the latter increased. The presence of these remaining lipids may not necessarily be negative, as numerous unsaturated long-chain fatty acids are required in our diets, and may lend potential health benefits (Kromhout, 2001; Conklin, 2002).

Visual comparison of the lipids analyzed by the Mojonnier method show that the lipids recovered from SFE were white to yellow, and solid at room temperature, while the lipids that were not extractable from the samples, once recovered by the Mojonnier procedure, were clear to transparent in color and liquid at room temperature. This indicates that $\mathrm{SC}-\mathrm{CO}_{2}$ in this system preferentially works on the polarity of the lipids than on the difference of their MW. This can be explained in the sense that SFE in this system works more like solid phase extraction of the very complex milk lipids, and the polarities of the material that interact with the lipids and $\mathrm{SC}-\mathrm{CO}_{2}$ have as end result a fractionation by polarity of lipids.

In this study we used the particle size analysis as an indicator of the integrity of the components in the powders once they were fully re-hydrated for at least $12 \mathrm{~h}$. As can be seen in Figure 3, buttermilk from reconstituted powder show a complex distribution of particles. It can be argued that those in the range from 0.04 to $0.2 \mu \mathrm{m}$ correspond to casein micelles and small aggregates of the micelles. Those particles in the range 0.4 to $4 \mu \mathrm{m}$ are observed with regularity in buttermilk 
and are presumably the skim milk vesicles and undisrupted small fat globules (Walstra et al., 1999). This curve changes dramatically after SFE treatment, and a large $110 \mu \mathrm{m}$ average particle is detected. We speculate that these particles are generated as colloidal insoluble complex aggregates derived from the SFE heat and lipid depletion. Although these particles exact composition was not fully characterized, they are for the most part a mixture of proteins, phospholipids, and in the case of BM, lactose. Regardless of these particles exact composition it is interesting to note that the microfiltration fraction seems to be less sensitive to changes induced by SFE, as judged from the very small change in the average mean particle and distribution (Figure 3).

In conclusion, the products developed by this process are rich in polar lipids and protein, and will be useful for studies at all levels on these dairy components. A deeper understanding of their metabolic effects and their mechanisms is important before substantiated claims can be made of their nutritional values or biological activities. Indeed, knowledge of their metabolic effects may imply that tailoring dietary manipulations to reduce or increase sphingomyelin and ceramide production/turnover may lead to an increased control over health.

\section{ACKNOWLEDGMENTS}

This work was funded in part by Dairy Management, Inc., and the California State University Agricultural Research initiative.

We thank Jerry Mattas and Harit K. Vyas for their contributions to this research.

\section{REFERENCES}

Bajjalieh, S. M., and R. H. Batchelor. 1999. Ceramide Kinase. Sphingolipid Metabolism and Cell Signaling. Meth. Enzymol. 311:207-215.

Batrakov, S. G., A. E. Mosezhnyi, A. O. Ruzhitsky, V. I. Sheichenko, and D. I. Nikitin. 2000. The polar-lipid composition of the sphingolipid-producing bacterium Flectobacillus major. Biochim. Biophys. Acta. 1484:225-240.

Berg, H., M. Magard, G. Johansson, and L. Mathiasson. 1997. Development of a supercritical fluid extraction method for determination of lipid classes and total fat in meats and its comparison with conventional methods. J. Chromatogr. A. 745:345-352.

Boyd, L. C., N. C. Drye, and A. P. Hansen. 1999. Isolation and characterization of whey phospholipids. J. Dairy Sci. 82(12):2550-2557.

Cheryan, M. 1998. Ultrafiltration and Microfiltration Handbook. CRC Press, Boca Raton, FL.

Christie, W. W. 1982. Lipid Analysis: Isolation, Separation, Identification and Structural Analysis of Lipids. 2nd Edition. Pergamon Press Inc., New York.

Colombo, B. B., E. Sottocornola, and A. Giacosa. 2002. Dietary sphingolipids in colorectal cancer prevention. Eur. J. Cancer Prev. 11(2):193-197.

Conklin, K. A. 2002. Dietary polyunsaturated fatty acids: Impact on cancer chemotherapy and radiation. Altern. Med. Rev. 7(1):4-21.
Cutler, R. G., and M. P. Mattson. 2001. Sphingomyelin and ceramide as regulators of development and lifespan. Mech. Ageing Dev. 122:895-908.

Dillehay, D. L., S. K. Webb, E.-M. Schmelz, and A. H. Merrill. 1994. Dietary sphingomyelin inhibits 1,2-dimethylhyrdrazine-induced colon cancer in CFI mice. J. Nutr. 124:615-620.

Enomoto, A., K. Nakamura, M. Hakoda, and N. Amaya. 1997. Lethal effect of high pressure carbon dioxide on a bacterial spore. J. Ferment. Bioeng. 83(3):305-307.

Folch, J., M. Lees, and G. H. Sloane-Stanley. 1957. A simple method for the isolation and purification of total lipids from animal tissues. J. Biol. Chem. 226:497-509.

González-Vila, F. J., J. M. Bautista, A. Gutiérrez, J. C. Del Rio, and A. G. González. 2000. Supercritical carbon dioxide extraction of lipids from Eucalyptus globules wood. J. Biochem. Biophys. Methods 43:345-351.

Hauthal, W. H. 2001. Advances with supercritical fluids [review]. Chemosphere 43:123-135.

Hidari, K., I.-P. Jwa, S. Ichikawa, T. Fujita, H. Sakiyama, and Y. Hirabayashi. 1996. Complete removal of sphingolipids from the plasma membrane disrupts cell to substratum adhesion of mouse melanoma cells. J. Biol. Chem. 271(24):14636-14641.

Hopper, M. L., and J. W. King. 1991. Enhanced supercritical fluid carbon dioxide extraction of pesticides from foods using pelletized diatomaceous earth. J. AOAC 74(4):661-666.

Huwiler, A., T. Kolter, J. Pfeilschifter, and K. Sandhoff. 2000. Physiology and pathophysiology of sphingolipid metabolism and signaling. Biochim. Biophys. Acta. 1485:63-99.

Kim, H. H. Y., and R. Jiménez-Flores. 1995. Heat induced interactions between proteins of the milk fat globule membrane and skim milk. J. Dairy Sci. 78:24-35.

Kim, M.-Y., C. Linardic, L. Obeid, and Y. Hannun. 1991. Identification of sphingomyelin turnover as an effector mechanism for the action of tumor necrosis factor alpha and gamma-interferon. J. Biol. Chem. 266(1):484-489.

King, J. W., A. Mohamed, S. L. Taylor, T. Mebrahtu, and C. Paul. 2001. Supercritical fluid extraction of Vernonia galamensis seeds. Industrial Crops and Products. 14:241-249.

Kromhout, D. 2001. Diet and cardiovascular diseases. J. Nutr. Health Ageing 5(3):144-149.

Lambertsen, G., and E. N. Christiansen. 1997. Milk fat: Nutrition and product development. Scandinavian J. Nutr. 41:88-90.

Lefèvre, T., and M. Subirade. 2000. Interaction of $\beta$-lactoglobulin with phospholipid bilayers: A moleculal level elucidation as revealed by infrared spectroscopy. Int. J. Biol. Macromol. 28:59-67.

Lightle, S. A., J. I. Oakley, and M. N. Nikolova-Karakashian. 2000. Activation of sphingolipid turnover and chronic generation of ceramide and sphingosine in liver during ageing. Mech. Ageing Dev. 120:111-125.

Markom, M., H. Singh, and M. Hasan. 2001. Supercritical carbon dioxide fractionation of crude palm oil. J. Supercritical Fluids 20:45-53.

Mather, I. 2000. A review and proposed nomenclature for major proteins of the milk-fat globule membrane. J. Dairy Sci. 83: 203-247.

Marshall, R. T. 1992. Standard Methods For the Examination of Dairy Products, 16th Ed. The Am. Publ. Health Association, Inc., Washington D.C.

Modrak, D. E., M. D. Rodriguez, D. M. Goldenberg, W. Lew, and R. D. Blumenthal. 2002. Sphingomyelin enhances chemotherapy efficacy and increases apoptosis in human colonic tumor xenografts. Int. J. Oncol. 20(2):379-384.

Molkentin, J. 2000. Occurrence and biochemical characteristics of natural bioactive substances in bovine milk lipids. Br. J. Nutr. 84(1):S47-S55.

Montanari, L., P. Fantozzi, J. M. Snyder, and J. W. King. 1999. Selective extraction of phospholipids from soybeans with supercritical carbon dioxide and ethanol. J. Supercritical Fluids. 14:87-93

Nava, V. E., O. Cuvillier, L. C. Edsall, K. Kimura, S. Milstien, E. P. G., and S. Spiegel. 2000. Sphingosine enhances apoptosis of 
radiation-resistant prostate cancer cells. Cancer Res. 60:4468-4474.

Okazaki, T., R. M. Bell, and Y. A. Hannun. 1989. Sphingomyelin turnover induced by vitamin $\mathrm{D}_{3}$ in HL-60 cells: Role in cell differentiation. J. Biol. Chem. 269:19,076-19,080.

Parodi, P. W. 1997. Cows' milk fat components as potential anticarcinogenic agents. J. Nutr. 127:1055-1060.

Rozzi, N. L., and R. K. Singh. 2000. Supercritical fluids and the food industry. Comprehensive Rev. Food Sci. Food Safety 1:33-34.

Rónyai, E., B. Simándi, S. Tömösközi, A. Deák, L. Vigh, and Az. Weinbrenner. 1998. Supercritical fluid extraction of corn germ with carbon dioxide-ethyl alcohol mixture. J. Supercritical Fluids. 14:75-81.

Samuelsson, G., P. Dejmek, G. Trägårdh, and M. Paulsson. 1997. Minimizing whey protein retention in cross-flow microfiltration of skim milk. Int. Dairy J. 7:237-242.

Sawai, H., and Y. A. Hannun. 2000. Ceramide and sphingomyelinases in the regulation of stress responses. Chem. Phys. Lipids. 102:141-147.

Smelt, J. P. P. M., and G. G. F. Rijke. 1992. High pressure treatment as a tool for pasteurization of foods. High Pressure Biotech. 224:361.

Sovová, H., R. P. Stateva, and A. A. Galushko. 2001. Essential oils from seeds: solubility of limonene in supercritical carbon dioxide and how it is affected by fatty oil. J. Supercritical Fluids. 20:113-129.

Spilimbergo, S., N. Elvassore, and A. Bertucco. 2002. Microbial inactivation by high-pressure. J. Supercritical Fluids. 22:55-63.
Stewart, C. M., C. P. Dunne, A. Sikes, and D. G. Hoover. 2000. Sensitivity of spores of Bacillus subtilis and Clostridium sporogenes PA3679 to combinations of high hydrostatic pressure and other processing parameters. Innovative Food Sci. Emerging Technol. 1:49-59.

Turner, C., and L. Mathiasson. 2000. Determination of vitamins A and $\mathrm{E}$ in milk powder using supercritical fluid extraction for sample clean-up. J. Chromatogr. A. 874:275-283.

Turner, C., J. W. King, and L. Mathiasson. 2001. Supercritical fluid extraction and chromatography for fat-soluble vitamin analysis J. Chromatogr. A. 936:215-237.

USDA 2001. National Agricultural Satatistics Service Bulletin.

Vyas, H. J. C. Astaire and R. Jiménez-Flores. 2002. Optimization of Microfiltration Process to Fractionate Buttermilk by Crossflow Microfiltration. Presented at the ADSA annual meeting, Quebec, CA.

Walstra, P., T. J. Geurts, A. Noomen, A. Jellema, and M. A. J. S. van Boekel. 1999. Dairy Technology_-Principles of Milk Properties and Processes. O. R. Fennema, Marcus Karel, Gary W. Sanderson, Steven R. Tannenbaum, Pieter Walstra, and John R. Whitaker, ed. Marcel Dekker, Inc., New York.

Watkins, S. M., T. Y. Lin, R. M. Davis, J. R. Ching, E. J. De Peters, G. M. Halpern, R. L. Walzem, and B. J. German. 2001. Unique phospholipid metabolism in mouse heart in response to dietary docosahexaenoic or linolenic acids. Lipids 36(3):247-254.

Ye, A., G. Singh, M. W. Taylor, and S. Anema. 2002. Characterization of protein components of natural and heat-treated milk fat globule membranes. Int. Dairy J. 12:393-402. 